\title{
Physician empathy: definition, components, measurement, and relationship to gender and specialty
}

\author{
Mohammadreza Hojat \\ Thomas Jefferson University \\ Joseph S. Gonnella \\ Thomas Jefferson University \\ Thomas J. Nasca \\ Thomas Jefferson University \\ Salvatore Mangione MD \\ Thomas Jefferson University \\ MififhachiYerqara additional works at: https://jdc.jefferson.edu/crmehc \\ Thomas Jefferson University \\ Part of the Psychiatry Commons \\ Let us know how access to this document benefits you
}

\section{Recommended Citation}

Hojat, Mohammadreza; Gonnella, Joseph S.; Nasca, Thomas J.; Mangione, Salvatore MD;

Vergare, Michael; and Magee, Michael, "Physician empathy: definition, components, measurement, and relationship to gender and specialty" (2002). CRMEHC Faculty Papers. Paper

4.

https://jdc.jefferson.edu/crmehc/4

This Article is brought to you for free and open access by the Jefferson Digital Commons. The Jefferson Digital Commons is a service of Thomas Jefferson University's Center for Teaching and Learning (CTL). The Commons is a showcase for Jefferson books and journals, peer-reviewed scholarly publications, unique historical collections from the University archives, and teaching tools. The Jefferson Digital Commons allows researchers and interested readers anywhere in the world to learn about and keep up to date with Jefferson scholarship. This article has been accepted for inclusion in CRMEHC Faculty Papers by an authorized administrator of the Jefferson Digital Commons. For more information, please contact: JeffersonDigitalCommons@jefferson.edu. 


\section{Authors}

Mohammadreza Hojat, Joseph S. Gonnella, Thomas J. Nasca, Salvatore Mangione MD, Michael Vergare, and Michael Magee 


\section{Physician Empathy: Definition, Components, Measurement, and Relationship to Gender and Specialty}

\author{
Mohammadreza Hojat, Ph.D. \\ Joseph S. Gonnella, M.D. \\ Thomas J. Nasca, M.D. \\ Salvatore Mangione, M.D. \\ Michael Vergare, M.D. \\ Michael Magee, M.D.
}

\begin{abstract}
Objective: There is a dearth of empirical research on physician empathy despite its mediating role in patient-physician relationships and clinical outcomes. This study was designed to investigate the components of physician empathy, its measurement properties, and group differences in empathy scores.
\end{abstract}

Method: A revised version of the Jefferson Scale of Physician Empathy (with 20 Likert-type items) was mailed to 1,007 physicians affiliated with the Jefferson Health System in the greater Philadelphia region; 704 (70\%) responded. Construct validity, reliability of the empathy scale, and the differences on mean empathy scores by physicians' gender and specialty were examined.

Results: Three meaningful factors emerged (perspective taking, compassionate care, and standing in the patient's shoes) to provide support for the construct validity of the empathy scale that was also found to be internally consistent with relatively stable scores over time. Women scored higher than men to a degree that was nearly significant. With control for gender, psychiatrists scored a mean empathy rating that was significantly higher than that of physicians specializing in anesthesiology, orthopedic surgery, neurosurgery, radiology, cardiovascular surgery, obstetrics and gynecology, and general surgery. No significant difference was observed on empathy scores among physicians specializing in psychiatry, internal medicine, pediatrics, emergency medicine, and family medicine.

Conclusions: Empathy is a multidimensional concept that varies among physicians and can be measured with a psychometrically sound tool. Implications for specialty selection and career counseling are discussed.

(Am J Psychiatry 2002; 159:1563-1569)

The patient-physician relationship is the center of medicine. (1, p. 148)

\footnotetext{
I
}

$\mathrm{n}$ a series of reports by the Association of American Medical Colleges on the Medical School Objectives Project (2), it was stated that medical schools are expected to educate altruistic physicians who "must be compassionate and empathetic in caring for patients." Physicians' understanding of a patient's perspective-and their expression of caring, concern, and empathy-are among the listed educational objectives (p. 13). However, without a conceptual framework and an operational measure of physician empathy, it is not possible to assess the degree to which these objectives are ever achieved.

Although researchers agree on the positive role of empathy in interpersonal relationships (3), they are divided on the definition and, hence, the measurement of empathy (4). Similarly, research on empathy in medicine has been hampered both by a lack of conceptual clarity and lack of an operational measure of physician empathy.

Empathy has been described as a concept involving cognitive as well as affective or emotional domains (5). The cognitive domain of empathy involves the ability to understand another person's inner experiences and feelings and a capability to view the outside world from the other person's perspective (6). The affective domain involves the capacity to enter into or join the experiences and feelings of another person $(6,7)$. The affective relationships that elicit emotional response are conceptually more relevant to sympathy than to empathy (3).

Although the concepts of empathy and sympathy are often mistakenly tossed into one terminological basket, they should be distinguished in patient-care situations (8). Both concepts involve sharing, but empathetic physicians share their understanding, while sympathetic physicians share their emotions with their patients (9). The two concepts do not, however, function independently. For example, in one study (6), we found a correlation coefficient of 0.45 between the two.

Because sympathy, if excessive, could interfere with objectivity in diagnosis and treatment $(7,9)$, "compassionate detachment" has been used to describe the physician's empathetic concern for the patient while keeping sympathy at a reasonable distance to maintain an emotional balance $(9,10)$. Hence, an "affective distance" would be desirable to avoid bursts of emotions that might interfere with clinical neutrality and personal durability (11). 
In contrast, empathy has no restraining boundary because it is assumed that understanding is always beneficial in patient care. An abundance of empathy should never impede patient care. According to Bolognini (12), empathy is a complementary state of separateness and sharing, and its abundance adds to the crucial element of healing.

On the basis of the aforementioned conceptualization, we define empathy in patient-care situations as a cognitive attribute that involves an ability to understand the patient's inner experiences and perspective and a capability to communicate this understanding. Despite the mediating role empathy can play in improving clinical outcomes $(9,13)$, there is a dearth of empirical study on the topic in the medical literature. One reason cited for this scarcity is the absence of an operational measure of empathy that is specific to the physician-patient relationship (6).

Among the few research instruments for measuring empathy in the general population are the Interpersonal Reactivity Index, developed by Davis (14), the Hogan Empathy Scale (15), and Emotional Empathy, developed by Mehrabian and Epstein (16). A few methods of measuring empathy have also been developed for use in nursing. These include the Empathy Construct Rating Scale (17), the Empathic Understanding of Interpersonal Processes Scale (18), the empathy subtest of the Relation Inventory (19), and the Empathy Test (20). None of these scales was specifically developed to measure physician empathy and, therefore, may not capture the essence of empathetic care rendered by physicians.

Research indicates that empathy has been linked, theoretically or empirically, to a number of attributes, such as dutifulness (21), prosocial behavior (22), moral reasoning (23), good attitudes toward elderly patients (24), a reduction in malpractice litigation (25), competence in history taking and performance of physical examinations (26), patient satisfaction $(9,25)$, physician satisfaction $(27)$, better therapeutic relationships $(28,29)$, and good clinical outcomes (9). It has also been reported that women demonstrate more empathy than men $(6,30)$ and express more caring attitudes $(31,32)$.

Little empirical evidence is available to link empathy and physician specialty. In one study (33), general practice physicians ranked highest among different medical (physicians, nurses) and nonmedical (clergymen, lawyers) professions on empathy, warmth, and genuineness. In another study (34), no difference was observed in empathy among medical students with different specialty preferences. In a recent study (35), medical students who planned to pursue specialties such as family medicine and pediatrics scored higher on empathy measures than their counterparts who planned to pursue radiology or pathology. In one of our recent studies (36), physicians in "people-oriented" specialties (primary care, obstetrics and gynecology, emergency medicine, psychiatry, and medical subspecialties) scored a significantly higher average em- pathy rating than their counterparts in "technology-oriented" specialties (hospital-based specialties, surgery, and surgical subspecialties).

We designed this study to empirically examine the underlying structure of a newly developed scale of physician empathy and its reliability as well as to investigate differences on empathy scores between male and female physicians and among physicians in different specialties.

\section{Method}

\section{Participants}

Study participants included 704 physicians in the Jefferson Health System, which is affiliated with Thomas Jefferson University Hospital and Jefferson Medical College in the greater Philadelphia region. The mean age of the participants was 46.8 years $(\mathrm{SD}=10.5$, range $=29-87)$.

\section{Instrument}

A revised version of the Jefferson Scale of Physician Empathy (6) was used in this study. This scale was originally developed to measure the attitudes of medical students toward physician empathy in patient-care situations (the " $\mathrm{S}$ " version). The scale was constructed on the basis of an extensive review of the literature, followed by pilot studies with groups of practicing physicians, medical students, and residents. After several iterations and refinements, the Jefferson Scale of Physician Empathy included 20 Likert-type items answered on a 7-point scale ( $1=$ strongly disagree, $7=$ strongly agree).

Psychometric data in support of the construct validity and criterion-related validity (convergent and discriminant) and internal consistency reliability of the original Jefferson Scale of Physician Empathy (the "S" version) have been reported (6). Convergent validity was confirmed by significant correlations $(p<0.05)$ between scores on the empathy scale and conceptually relevant measures, such as compassion (for residents, $\mathrm{r}=0.56$; for medical students, $r=0.48$ ) (6). Also, significant correlations were observed between the Jefferson Scale of Physician Empathy and Interpersonal Reactivity Index (14) subtest scores for empathetic concern (for residents, $\mathrm{r}=0.40$; for medical students, $\mathrm{r}=0.41$ ), perspective taking (for residents, $r=0.27$; for medical students, $r=0.29$ ), and fantasy (for residents, $r=0.32$; for medical students, $r=0.24$ ) (6). Correlations of scores on the Jefferson Scale of Physician Empathy and self-ratings of empathy were 0.45 for residents and 0.37 for medical students (6). Discriminant validity was supported by the lack of a relationship between empathy and conceptually irrelevant measures such as self-protection $(r=0.11$, nonsignificant). Internal consistency reliability of the original scale was determined by coefficients alpha $(0.87$ for residents and 0.89 for medical students) (6).

We developed a revised version of the Jefferson Scale of Physician Empathy for physicians and health professionals (the "HP" version) for this study by slightly modifying the wording of the "S" version to make it more relevant to the caregiver's empathetic behavior rather than to empathetic perceptions (attitudes). The changes were made on the basis of the assumption that empathetic attitudes (perceptions) and behaviors (actions) are two different aspects of empathy (37) even though they are correlated.

For example, the following item is from the "S" version: "Because people are different, it is almost impossible for physicians to see things from their patients' perspectives" (6). It was revised to read as follows in the "HP" version: "Because people are different, it is almost impossible for me to see things from my patients' perspectives." These modifications were also intended to make 
the scale applicable to other health-care providers (e.g., nurses, psychotherapists, etc.), as well as physicians.

Furthermore, there were only three negatively worded items in the "S" version of the Jefferson Scale of Physician Empathy. Negatively worded items are usually used in psychological tests to decrease the confounding effect of the "acquiescence response style" (e.g., the tendency to constantly agree or disagree by yeasayers and naysayers). In the "HP" version, a balance was maintained by making 10 items positively worded and 10 items negatively worded. Questions were also included about respondents' gender and primary areas of practice. (Copies of the "S" and "HP" versions of the Jefferson Scale of Physician Empathy can be obtained from the first author.)

\section{Procedures}

The Jefferson Scale of Physician Empathy was mailed to 1,007 physicians. Each was accompanied by a cover letter signed by one of the authors (T.J.N.) to increase cooperation. A handwritten note was included on the cover letter for many of the physicians who were personally known to the author who signed the letters.

The respondents were instructed not to identify themselves and were assured about the strict confidentiality of individual responses. An addressed, postage-paid envelope was provided for return of the survey. Two follow-up reminders were sent to nonrespondents at 4 - and 8-week intervals after the original mailing. A total of 704 completed surveys were returned, representing a $70 \%$ response rate.

For the purpose of studying the test-retest reliability of the Jefferson Scale of Physician Empathy, a group of 100 physicians who responded to the survey were randomly selected. They were sent a second copy of the Jefferson Scale of Physician Empathy with a thank-you note for their participation and a request to complete the second copy of the empathy scale for the purpose of the reliability study. Seventy-one physicians responded, and their scores from the two tests were correlated. The exact time interval between completion of the two tests could not be accurately determined because we did not ask the physicians to specify the date on which they completed the questionnaires. On the basis of the postmarks, we estimated that the testing interval was approximately 3-4 months.

\section{Statistical Analyses}

To investigate the underlying components of the Jefferson Scale of Physician Empathy ("HP" version), data were subjected to principal-component factor analysis by using orthogonal rotation to obtain a simpler factor structure. A t test was also used to compare the scores of men and women, and analysis of variance was used to examine the differences on the mean empathy scores among physicians in different specialties. Because of the small number of women in some of the specialties, we used analysis of covariance (ANCOVA) (with gender as a covariate) instead of a two-way analysis of variance (with gender and specialty as the independent variables) to control for the effect of gender on empathy scores for physicians in different specialties.

\section{Results}

The response rate achieved in this study (70\%) is considerably higher than the typical rate of $52 \%$ reported for mailed surveys to physicians (38). But according to Gough and Hall (39), a response rate of at least $75 \%$ should be achieved to ensure representativeness of the sample for mailed surveys to professionals. Since our response rate was lower than $75 \%$, we compared the respondents and nonrespondents on their specialties (the only variable available to us for nonrespondents) to ensure that the respondents were representative in that regard. No significant difference in specialties was observed between the respondents and the nonrespondents.

\section{Components of the Empathy Scale}

To examine the underlying factors (components) of the empathy scale, an exploratory factor analysis was conducted that produced three meaningful factors with eigenvalues greater than one. The first factor accounted for $21 \%$, the second factor for $8 \%$, and third factor for $7 \%$ of the total variance. The magnitudes of the eigenvalues, proportions of variance, and factor coefficients are reported in Table 1.

As shown in the table, the 10 positively worded items had factor coefficients greater than 0.35 for factor 1 (shown in bold). On the basis of the content of these items and the magnitude of the eigenvalue, the first factor can be considered the grand factor of perspective taking, the core ingredient of empathy $(5,13,14)$. This factor is very similar to the grand factor of physician's view from patient's perspective that emerged in the "S" version of the scale (6).

Eight of the negatively worded items had factor coefficients greater than 0.35 for factor 2 . On the basis of the content of these items, this factor can be considered a construct involving "compassionate care" (which is in opposition to the negatively worded items' contents)—similar to the emotions in patient care that emerged in the "S" version (6). Finally, two other negatively worded items had high coefficients for factor 3 , titled the ability to stand in the patient's shoes (which is in contrast to the negatively worded items' contents). This factor is also similar to thinking like the patient, which is found in the " $\mathrm{S}$ " version of the scale (6).

The factor structure of the Jefferson Scale of Physician Empathy is consistent with the conceptual aspects of a multidimensionality notion of empathy $(4,14)$. The stability of factor structure and factor similarity across different groups (medical students and practicing physicians) and across different forms (the "S" and "HP" versions) provide further support for the construct validity of the scale.

\section{Descriptive Statistics and Reliability Coefficients}

Score distribution and descriptive statistics for the Jefferson Scale of Physician Empathy ("HP" version) are reported in Table 2. The internal consistency of the empathy scale was examined by calculating Cronbach's coefficient alpha. This reliability coefficient was 0.81 , indicating that the Jefferson Scale of Physician Empathy is internally consistent. The test-retest reliability coefficient was 0.65 , suggesting that the empathy scores were relatively stable over time.

\section{Gender Difference and Age}

We compared the empathy scores for 507 men and 179 women who reported their gender. The mean empathy score for men (mean=119.1, SD=11.8) was slightly lower than that for women (mean=120.9, SD=12.2), and the dif- 


\begin{tabular}{|c|c|c|c|}
\hline \multirow[b]{2}{*}{ Item } & \multicolumn{3}{|c|}{ Factor } \\
\hline & 1 & 2 & 3 \\
\hline $\begin{array}{l}\text { 1. An important component of the relationship with my patients is my understanding of the emotional } \\
\text { status of the patients and their families. }\end{array}$ & 0.70 & 0.21 & -0.08 \\
\hline $\begin{array}{l}\text { 2. I try to understand what is going on in my patients' minds by paying attention to their nonverbal } \\
\text { cues and body language. }\end{array}$ & 0.62 & 0.06 & 0.23 \\
\hline 3. I believe that empathy is an important therapeutic factor in medical treatment. & 0.60 & 0.28 & -0.25 \\
\hline 4. Empathy is a therapeutic skill without which my success as a physician would be limited. & 0.58 & 0.22 & -0.16 \\
\hline $\begin{array}{l}\text { 5. My understanding of my patients' feelings gives them a sense of validation that is therapeutic in its } \\
\text { own right. }\end{array}$ & 0.58 & 0.32 & 0.03 \\
\hline 6. My patients feel better when I understand their feelings. & 0.50 & -0.02 & 0.16 \\
\hline $\begin{array}{l}\text { 7. I consider understanding my patients' body language as important as verbal communication in } \\
\text { physician-patient relationships. }\end{array}$ & 0.48 & -0.18 & 0.30 \\
\hline 8. I try to imagine myself in my patients' shoes when providing care to them. & 0.46 & 0.29 & 0.28 \\
\hline 9. I have a good sense of humor, which I think contributes to a better clinical outcome. & 0.45 & -0.02 & 0.14 \\
\hline 10. I try to think like my patients in order to render better care. & 0.46 & 0.20 & 0.25 \\
\hline $\begin{array}{l}\text { 11. Patients' illnesses can be cured only by medical treatment; therefore, affectional ties to my patients } \\
\text { cannot have a significant place in this endeavor. }{ }^{b}\end{array}$ & 0.17 & 0.60 & -0.01 \\
\hline 12. Attentiveness to my patients' personal experiences is irrelevant to treatment effectiveness. ${ }^{\text {b }}$ & 0.07 & 0.59 & 0.07 \\
\hline 13. I try not to pay attention to my patients' emotions in interviewing and history taking. ${ }^{\text {b }}$ & 0.02 & 0.54 & 0.02 \\
\hline 14. I believe that emotion has no place in the treatment of medical illness. ${ }^{b}$ & 0.22 & 0.50 & -0.03 \\
\hline $\begin{array}{l}\text { 15. I do not allow myself to be touched by intense emotional relationships among my patients and their } \\
\text { family members. }\end{array}$ & 0.13 & 0.44 & 0.26 \\
\hline $\begin{array}{l}\text { 16. My understanding of how my patients and their families feel is an irrelevant factor in medical } \\
\text { treatment. }^{b}\end{array}$ & -0.03 & 0.43 & 0.14 \\
\hline 17. I do not enjoy reading nonmedical literature or experiencing the arts. ${ }^{b}$ & 0.05 & 0.37 & 0.13 \\
\hline $\begin{array}{l}\text { 18. I consider asking patients about what is happening in their lives an unimportant factor in } \\
\text { understanding their physical complaints. }\end{array}$ & 0.10 & 0.37 & -0.12 \\
\hline 19. It is difficult for me to view things from my patients' perspectives. ${ }^{b}$ & 0.10 & 0.05 & 0.74 \\
\hline $\begin{array}{l}\text { 20. Because people are different, it is almost impossible for me to see things from my patients' } \\
\text { perspectives. }\end{array}$ & 0.17 & 0.20 & 0.66 \\
\hline Eigenvalue & 4.2 & 1.5 & 1.3 \\
\hline$\%$ variance & 21 & 8 & 7 \\
\hline
\end{tabular}

${ }^{a}$ Items are listed by the order of magnitude of the factor structure coefficients within each factor. Values greater than 0.35 are in bold. Responses were based on a 7-point Likert-type scale.

${ }^{\mathrm{b}}$ Responses were reverse-scored on these items (strongly agree $=1$, strongly disagree $=7$ ); otherwise, items were scored directly (strongly agree $=7$, strongly disagree $=1$ ).

ference between genders was nearly significant $(t=1.71$, $\mathrm{df}=684, \mathrm{p}=0.08$ ). Age did not significantly correlate with empathy scores for men $(\mathrm{r}=0.01)$ or women $(\mathrm{r}=0.07)$.

\section{Specialty Comparisons}

We compared the mean empathy scores for physicians in 12 different specialty groups. For a meaningful comparison, only the specialties reported by more than 20 physicians were included in this analysis. Statistically significant differences were found in empathy scores among physicians in different specialties $(\mathrm{F}=1.99, \mathrm{df}=11,493$, $\mathrm{p}<0.05$ ) (Table 3).

The specialties in Table 3 are listed in descending order of magnitude of mean empathy scores. Psychiatrists had the highest mean empathy score (mean=127.0), followed by physicians in general internal medicine (mean=121.7), general pediatrics (mean=121.5), emergency medicine (mean=121.0), and family medicine $($ mean $=120.5)$. The lowest means were scored by physicians in anesthesiology $($ mean $=116.1)$, orthopedic surgery $($ mean $=116.5)$, neurosurgery (mean $=117.3)$, radiology (mean=117.9), and cardiovascular surgery (mean $=118.0$ ). Physicians in general surgery (mean=119.3) and obstetrics and gynecology (mean=119.2) had scores that fell between these high- and low-scoring specialties. The differences in em- pathy scores among psychiatrists and physicians in internal medicine, pediatrics, and emergency medicine were not statistically significant, but physicians in all other specialties scored significantly lower than psychiatrists ( $\mathrm{p}<0.05$, by Duncan's post hoc mean comparison test). When we controlled the effect of physician gender (by ANCOVA), the aforementioned differences among specialties remained unchanged with one exception-physicians in family medicine were among the high scorers for empathy and were not significantly different from their counterparts in psychiatry, general internal medicine, general pediatrics, and emergency medicine. These results are consistent with our previous findings (36) and with findings reported by Newton and colleagues (35) but not with those reported by Harsch (34).

\section{Discussion}

A positive patient-physician relationship is a critical element in the practice of medicine and in the art of healing $(1,4,9,25)$; however, such relationships have been severely strained by changes in the economics of medical practice (1) as well as recent developments in the organization and delivery of health care (40). When one considers the many changes within the health-care system that 
TABLE 2. Distributions, Percentiles, and Descriptive Statistics for Scores on the Jefferson Scale of Physician Empathy of 704 Physicians

\begin{tabular}{|c|c|c|c|}
\hline Score Variable & Frequency & $\begin{array}{l}\text { Cumulative } \\
\text { Frequency }\end{array}$ & $\begin{array}{c}\text { Cumulative } \\
\%\end{array}$ \\
\hline \multicolumn{4}{|l|}{ Interval } \\
\hline$\leq 75$ & 3 & 3 & $<1$ \\
\hline $76-80$ & 3 & 6 & 1 \\
\hline $81-85$ & 2 & 8 & 1 \\
\hline $86-90$ & 3 & 11 & 2 \\
\hline $91-95$ & 13 & 24 & 3 \\
\hline 96-100 & 21 & 45 & 6 \\
\hline 101-105 & 31 & 76 & 11 \\
\hline $106-110$ & 57 & 133 & 19 \\
\hline $111-115$ & 97 & 230 & 33 \\
\hline $116-120$ & 111 & 341 & 48 \\
\hline $121-125$ & 114 & 455 & 65 \\
\hline $126-130$ & 126 & 581 & 83 \\
\hline 131-135 & 85 & 666 & 95 \\
\hline $136-140$ & 38 & 704 & 100 \\
\hline Mean & 120 & & \\
\hline SD & 12 & & \\
\hline \multicolumn{4}{|l|}{ Percentile } \\
\hline 25th & 113 & & \\
\hline 50th (median) & 121 & & \\
\hline 75th & 128 & & \\
\hline Possible range & $20-140$ & & \\
\hline Actual range & $50-140$ & & \\
\hline Alpha reliability estimate & 0.81 & & \\
\hline Test-retest reliability ${ }^{a}$ & 0.65 & & \\
\hline
\end{tabular}

may negatively influence the patient-physician alliance and undermine empathy in therapeutic relationships, it makes sense to begin studying the development and correlates of physician empathy and its contribution to clinical outcomes.

The findings of this study suggest that physician empathy is a multidimensional concept involving at least three components. The most important component is perspective taking, an outcome consistent with that reported for the general population $(5,13,14)$. Other components of empathy are compassionate care and standing in the patient's shoes, which are both specific to the patient-physician relationship.

Studies are inconsistent about how amenable empathy is to educational intervention among medical students and physicians. Some researchers believe that empathy is a personality state that can decline during medical education (41) but can also be improved by targeted educational activities $(42,43)$. Others report that empathy is a personality trait that cannot be easily taught $(44,45)$. We do not know which of the three components of empathy found in this study is more or less amenable to educational interventions in training physicians, nor do we know which of the physician's three professional roles as clinician, educator, and resource manager (46) can be enhanced by increasing his/her empathy. Further empirical research is needed to address these issues.

It is important to investigate the underlying reasons for variations in empathy among health-care professionals. For example, although it did not reach statistical signifi-
TABLE 3. Scores of 704 Physicians on the Jefferson Scale of Physician Empathy by Gender and Specialty

\begin{tabular}{|c|c|c|c|}
\hline Gender and Specialty & $\mathrm{N}$ & Mean & SD \\
\hline \multicolumn{4}{|l|}{ Gender $^{\mathrm{a}}$} \\
\hline Men & 507 & 119.1 & 11.8 \\
\hline Women & 179 & 120.9 & 12.2 \\
\hline \multicolumn{4}{|l|}{ Specialty $^{\mathrm{b}}$} \\
\hline Psychiatry & 24 & 127.0 & 5.5 \\
\hline Internal medicine & 60 & 121.7 & 10.6 \\
\hline Pediatrics & 78 & 121.5 & 12.2 \\
\hline Emergency medicine & 23 & 121.0 & 10.7 \\
\hline Family medicine & 69 & 120.5 & 12.6 \\
\hline General surgery & 33 & 119.3 & 14.9 \\
\hline Obstetrics/gynecology & 24 & 119.2 & 10.4 \\
\hline Cardiovascular surgery & 44 & 118.0 & 13.2 \\
\hline Radiology & 43 & 117.9 & 13.1 \\
\hline Neurosurgery & 21 & 117.3 & 9.5 \\
\hline Orthopedic surgery & 24 & 116.5 & 12.9 \\
\hline Anesthesiology & 51 & 116.1 & 12.0 \\
\hline
\end{tabular}

cance in this study, the finding that women tend to score higher on empathy ratings than men is consistent with the findings of other studies $(30,47)$, but it falls short of providing an explanation for gender differences in empathy.

Several explanations can be offered for gender differences in empathy. For example, it has been suggested that women are more receptive than men to emotional signals (48), a quality that can contribute to a better understanding and, hence, to a better empathetic relationship (47). Also, on the basis of the evolutionary theory of parental investment, women are believed to develop more caregiving attitudes toward their offspring than men (48). The findings on gender differences in empathy are in agreement with the reports that female physicians spend more time with their patients, have fewer patients (49), and render more preventive and patient-oriented care $(50,51)$.

More empirical evidence is needed to test the hypothesis that relates gender differences on empathy to intrinsic (e.g., evolutionary gender characteristics) or to extrinsic (e.g., gender role expectations) factors (30). Each hypothesis has potentially different implications in the selection and training of physicians.

The significant differences in empathy scores observed among physicians in various specialties might reflect the notion that different individuals with different degrees of interpersonal skills, reflected in their empathy scores, are attracted to different specialties (34). These differences might also result from the amount of emphasis in training that is placed on interpersonal skills in different specialties. Each of these notions has implications in the selection, career counseling, and curriculum development of academic medical centers.

Prospective studies might well be conducted to examine the relationship between empathy scores and performance measures in medical school, to address changes in empathy at different levels of undergraduate and graduate 
medical education, and to investigate the long-term effects of physician empathy on patient satisfaction, clinical outcomes, and malpractice litigation.

This study is a step toward clarification and measurement of physician empathy. The definition and measurement of empathy deserves attention because this essential humanistic aspect of medicine eludes the performance measures that are commonly used in medical education. Such research could have important implications in the selection and education of medical students and residents and in career counseling. The Jefferson Scale of Physician Empathy that was used in this study, supported by construct validity, test-retest, and internal consistency reliabilities, provides a psychometrically sound tool for future research on physician empathy.

Received Nov. 16, 2001; revision received April 10, 2002; accepted April 22, 2002. From the Center for Research in Medical Education and Health Care and the Department of Psychiatry and Human Behavior, Jefferson Medical College, Thomas Jefferson University. Address reprint requests to Dr. Hojat, Center for Research in Medical Education and Health Care, Jefferson Medical College, 1025 Walnut St., Philadelphia, PA 19107; mohammadreza.hojat@mail.tju.edu (email).

Supported in part by a grant from the Pfizer Medical Humanities Initiative of Pfizer, Inc.

The authors thank Dorissa Bolinski for editorial assistance.

\section{References}

1. Glass RM: The patient-physician relationship: JAMA focuses on the center of medicine (editorial). JAMA 1996; 275:147-148

2. Association of American Medical Colleges (AAMC) Medical School Objectives Project. http://www.aamc.org/meded/msop

3. Stephan WG, Finlay KA: The role of empathy in improving inter-group relations. J Soc Issues 1999; 55:729-743

4. Kunyk D, Olson JK: Clarification of conceptualizations of empathy. J Adv Nurs 2001; 35:317-325

5. Davis MH: Empathy: A Social Psychological Approach. Madison, Wis, Brown and Benchmark, 1994

6. Hojat M, Mangione S, Nasca TJ, Cohen MJM, Gonnella JS, Erdmann JB, Veloski JJ, Magee M: The Jefferson Scale of Empathy: development and preliminary psychometric data. Educational and Psychol Measurement 2001; 61:349-365

7. Aring CD: Sympathy and empathy. JAMA 1958; 167:448-452

8. Wispe L: The distinction between sympathy and empathy: to call forth a concept, a word is needed. J Pers Soc Psychol 1986; 50:314-321

9. Nightingale SD, Yarnold PR, Greenberg MS: Sympathy, empathy, and physician resource utilization. J Gen Intern Med 1991; 6:420-423

10. Blumgart HL: Caring for the patient. N Engl J Med 1964; 270: 449-456

11. Jensen N: The empathic physician (letter). Arch Intern Med 1994; 154:108

12. Bolognini S: Empathy and “empathism.” Int J Psychoanal 1997; 78:279-293

13. Spiro HM, McCrea Curen MG, Peschel E, St James D: Empathy and the Practice of Medicine: Beyond Pills and the Scalpel. New Haven, Conn, Yale University Press, 1993

14. Davis $\mathrm{MH}$ : Measuring individual differences in empathy: evidence for multidimensional approach. J Pers Soc Psychol 1983; 44:113-126
15. Hogan R: Development of an empathy scale. J Consult Clin Psychol 1969; 33:307-316

16. Mehrabian A, Epstein NA: A measure of emotional empathy. J Pers 1972; 40:525-543

17. LaMonica EL: Construct validity of an empathy instrument. Res Nurs Health 1981; 4:389-400

18. Carkhuff R: Helping and Human Relations: Selection and Training, vol 1. New York, Holt, Rinehart, and Winston, 1969

19. Barrett-Lennard GT: Dimensions of Therapist Response as Causal Factors in the Therapeutic Change. Psychol Monogr 1969; 76(43, number 562)

20. Layton JM: The use of modeling to teach empathy to nursing students. Res Nurs Health 1979; 2:163-176

21. Wolf ES: The dutiful physician: the central role of empathy in psychoanalysis, psychotherapy, and medical practice. Hillside J Clin Psychiatry 1980; 2:41-56

22. Batson CD, Polycarpou MP, Harmon-Jones E, Imhoff MJ, Mitchener EC, Bender LL: Empathy and attitudes: can feeling for a member of a stigmatized group improve feelings toward the group? J Pers Soc Psychol 1997; 72:105-118

23. Olsen DP: Development of an instrument to measure the cognitive structure used to understand personhood in patients. Nurs Res 1997; 46:78-84

24. Bagshaw M, Adams M: Nursing home nurses' attitudes, empathy, and ideologic orientation. Int J Aging Hum Dev 1986; 22: 235-246

25. Levinson W: Physician-patient communication: a key to malpractice prevention. JAMA 1994; 273:1619-1620

26. Colliver JA, Willis MS, Robbs RS, Cohen DS, Swartz MH: Assessment of empathy in a standardized-patient examination. Teach Learn Med 1998; 10:8-11

27. Suchman LA, Roter D, Green M, Lipkin M: Physician satisfaction with primary care office visits: Collaborative Study Group of the American Academy on Physician and Patient. Med Care 1993; 31:1083-1092

28. Bertakis KD, Roter D, Putman SM: The relationship of physician medical interview style to patient satisfaction. J Fam Pract 1991; 32:175-181

29. Livinson W, Roter D: Physicians' psychosocial beliefs correlate with their patient communication skills. J Gen Intern Med 1995; 10:375-379

30. Eisenberg N, Lennon R: Sex differences in empathy and related capacities. Psychol Bull 1983; 94:100-131

31. Eagly AH, Steffen VJ: Gender stereotypes stem from the distribution of men and women into social roles. J Pers Soc Psychol 1984; 46:735-754

32. Reverby S: A caring dilemma: womanhood and nursing in historical perspective. Nurs Res 1987; 36:1-5

33. Truax CB, Altmann H, Millis WA: Therapeutic relationships provided by various professionals. J Community Psychol 1974; 2: 33-36

34. Harsch $\mathrm{HH}$ : The role of empathy in medical students' choice of specialty. Acad Psychiatry 1989; 13:96-98

35. Newton BW, Savidge MA, Barber L, Cleveland E, Clardy J, Beeman G, Hart T: Differences in medical students' empathy. Acad Med 2000; 75:1215

36. Hojat M, Mangione S, Gonnella JS, Nasca T, Veloski JJ, Kane G: Empathy in medical education and patient care (letter). Acad Med 2001; 76:669

37. Kunst-Wilson W, Carpenter L, Poser A, Venhor I, Kushner K: Empathic perception of nursing students: self-reported and actual ability. Res Nurs Health 1981; 4:283-293

38. Cummings SA, Savitz LA, Konrad TR: Reported response rates to mailed physician questionnaires. Health Serv Res 2001; 35: 1347-1355 
39. Gough HG, Hall WB: A comparison of physicians who did or did not respond to a postal questionnaire. J Appl Psychol 1977; 62: 777-780

40. Hojat M, Gonnella JS, Erdmann JB, Veloski JJ, Louis DZ, Nasca TJ, Rattner SL: Physicians' perceptions of the changing health care system: comparisons by gender and specialties. J Community Health 2000; 25:455-471

41. Forest-Streit U: Differences in empathy: a preliminary analysis. J Med Educ 1982; 57:65-67

42. Goldstein AP, Goedhart A: The use of structured learning for empathy enhancement in paraprofessional psychotherapists. J Community Psychol 1973; 1:168-173

43. LaMonica EL, Carew DK, Winder AE, Bernazza-Hasse AM, Blanchard KH: Empathy training as the major thrust of a staff development program. Nurs Res 1976; 25:447-451

44. LaMonica EL, Wolf RM, Madea AR, Oberst MT: Empathy and nursing care outcomes. Sch Inq Nurs Pract 1987; 1:197-213

45. Kirk WG, Thomas AH: A brief in-service training strategy to increase levels of empathy of psychiatric nursing personnel. J Psychiatr Treat Eval 1982; 4:177-179
46. Gonnella JS, Hojat M: Biotechnology and ethics in medical education of the new millennium: physician roles and responsibilities. Med Teach 2001; 23:371-377

47. Hojat M, Gonnella JS, Mangione S, Nasca TJ, Veloski JJ, Erdmann JB, Callahan CA, Magee M: Empathy in medical students as related to academic performance, clinical competence, and gender. Med Educ 2002; 36:522-527

48. Trivers RL: Parental investment and sexual selection, in Sexual Selection and the Descent of Man. Edited by Campbell B. Chicago, Aldine, 1972, pp 136-179

49. Bertakis KD, Helms LJ, Callahan EJ, Azari R, Robbins JA: The influence of gender on physician practice style. Med Care 1995; 33:407-416

50. Maheux B, Duford F, Beland F, Jacques A, Lavesque A: Female medical practitioners: more preventive and patient oriented? Med Care 1990; 28:87-92

51. Hojat M, Gonnella JS, Xu G: Gender comparisons of young physicians' perceptions of their medical education, professional life, and practice: a follow-up study of Jefferson Medical College graduates. Acad Med 1995; 70:305-312 